\title{
DISTANT MOTIONS FROM A BUILDING VIBRATION TEST
}

\author{
By Paul C. Jennings
}

\begin{abstract}
Horizontal ground motion generated by vibration tests of the nine-story Millikan Library Building on the Caltech campus was recorded on the surface of the ground in the Pasadena area at distances up to 3 miles from the building. Later it was learned that the vertical component of the motion also was recorded by the seismograph on Mt. Wilson, 6.7 miles from the Library and 4,800 ft higher in elevation. The magnitude of the acceleration varied from $2.04 \times 10^{-2} \mathrm{~g}$ at the excitation level on the ninth floor of the building to $3.2 \times 10^{-7} \mathrm{~g}$ at Mt. Wilson. Simple calculations show that multistory buildings are particularly well-suited for inducing large dynamic forces in the ground with relatively small equipment.
\end{abstract}

\section{INTRODUCTION}

During the vibration tests of the nine-story Millikan Library Building at the California Institute of Technology (Jennings and Kuroiwa, 1968, Kuroiwa, 1967), buildinginduced motion was clearly recorded off campus at the Caltech Seismological Laboratory. The building is founded on approximately $900 \mathrm{ft}$ of alluvium overlying bedrock. After an additional test confirmed that the building vibration was indeed the source of the motion, an experiment was conducted to measure the surface motion in the Pasadena area. It was found that the motion could be measured easily by portable seismographs at distances up to 3 miles from the building site. After the test was completed, it was learned that the vertical component of the motion was recorded by the seismograph atop Mt. Wilson, 6.7 miles distant from the Library and 4,800 ft higher in elevation.

\section{Instrumentation and Test Procedures}

The building was excited into resonance in the N-S direction by two of the vibration generators developed at Caltech for the State Division of Architecture under the sponsorship of the Earthquake Engineering Research Institute. Details of the vibration generators, now the property of the University of California, and descriptions of their use in the Millikan Library tests are available in the literature (Hudson, 1962; Jennings and Kuroiwa, 1968; Kuroiwa, 1967). The accelerometer-recorder system used to measure the building motion and the motion on the nearby soil also has been described elsewhere (Kuroiwa, 1967).

The surface motion in the area not immediately adjacent to the Library was measured by six of the portable seismographic stations owned and developed by the Seismological Laboratory of the California Institute of Technology. These instruments use Ranger-type seismometers as the sensing element and record on film. Their characteristics have been described in a paper by F. E. Lehner and F. Press (1966).

Beginning at approximately 7 p.m., December 15 1966, the building was excited into resonance, using full weights in the eccentric mass vibrators. The fundamental mode in the N-S direction ( 1.92 cycles/sec) was chosen as this enabled the greatest amount of energy to be fed into the building by the two $1 \frac{1}{2}-\mathrm{hp}$ vibrators. As a result of this choice, all reported measurements with the exception of that from Mt. Wilson, are for N-S motion. The purpose of this first part of the test was to calibrate the seismo- 
graphic instruments as accelerometers at the chosen frequency by recording motion at the same point by both the seismometers and the accelerometers. The accelerometerrecorder system then was calibrated in a routine manner on a tilt table (Kuroiwa, 1967) to complete this portion of the experiment. The calibration point, shown in Figure 1, was chosen as far from the building as it was possible to obtain usable records with the accelerometers.

Later examination of the film records from the seismometers showed that the calibration was not completely successful in that the motion appeared to be too strong for the seismometers, although they were attenuated fully. The motion at the site was very nearly sinusoidal according to the accelerometers, but this was not the case on the

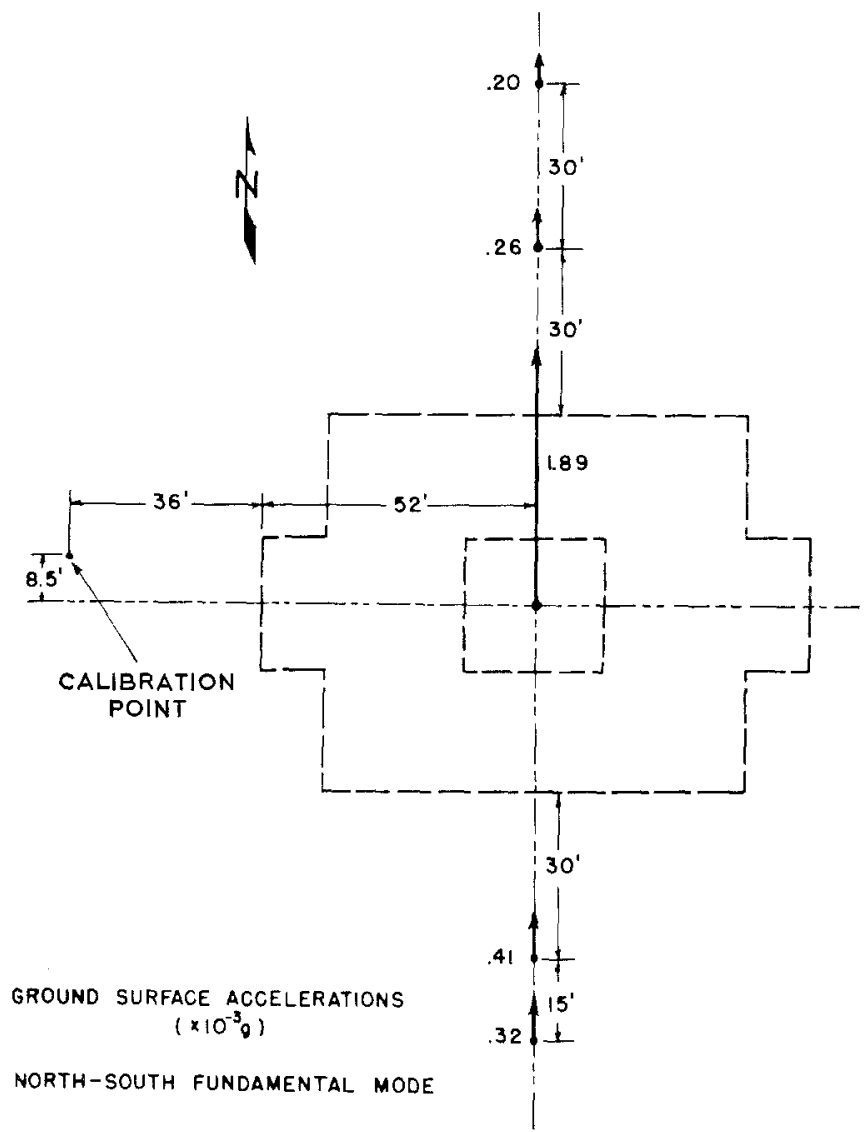

Fig. 1. Ground surface motions measured during vibrations in the N-S fundamental mode under the same loading conditions as the present test. The calibration point is on the left.

seismographic records. Also, the ratio of horizontal to vertical motion differed for the two sets of instruments. At sites more distant from the building than the calibration point, the seismographic records showed the expected sinusoidal motion. Thus, the building motions and the relative values of the ground surface motions away from the building site are judged to be reliable, but the absolute values of all ground surface motions are not known precisely. The calibration difficulties are thought not to affect the absolute values more than a factor of two, however, and the results are presented on the basis of a calibration performed with the measured horizontal motions.

After the calibration, five of the seismographic trailers were located permanently at selected points in the Pasadena area, whereas the sixth trailer was attached to a truck 
and readied to gather data at several sites. At 11 p.m., when the seismic noise from traffic, etc., had subsided substantially, the building was again put in resonance and maintained in that state for approximately $4 \mathrm{hr}$ while data were taken. During this

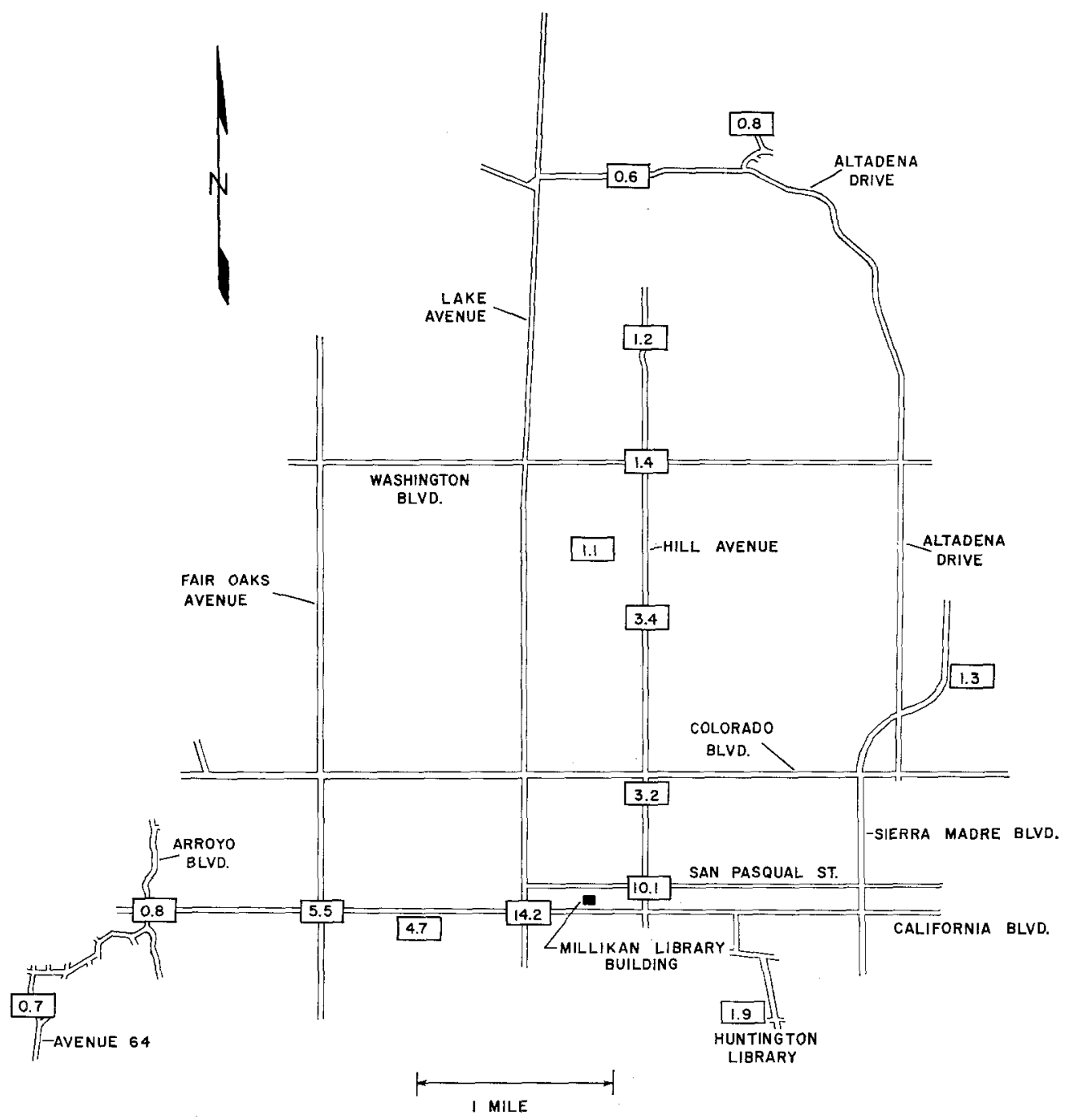

\section{NORTH-SOUTH RELATIVE SURFACE MOTION}

\section{MILLIKAN LIBRARY TESTS}

FIG. 2. Relative values of North-South surface motions recorded in the Pasadena area.

time, the vibration amplitude was constant within 5 per cent and the frequency within 1 per cent, according to accelerometers on the ninth floor and first floor of the building.

\section{Test Results}

The ground surface motion in the immediate vicinity of the building foundation is shown in Figure 1. These values are from a previous test (Kuroiwa, 1967) under the same loading conditions and are within 5 per cent of those measured in the present test as judged by the level of motion at the ninth and first floors of the building. The 
amplitude of the N-S acceleration at the level of excitation (ninth floor) in the present test was $2.0 \times 10^{-2} \mathrm{~g}$, whereas at the calibration point (Figure 1 ), the N-S acceleration had diminished to $1.2 \times 10^{-3} \mathrm{~g}$.

The relative values of the N-S surface motions recorded in the Pasadena area are

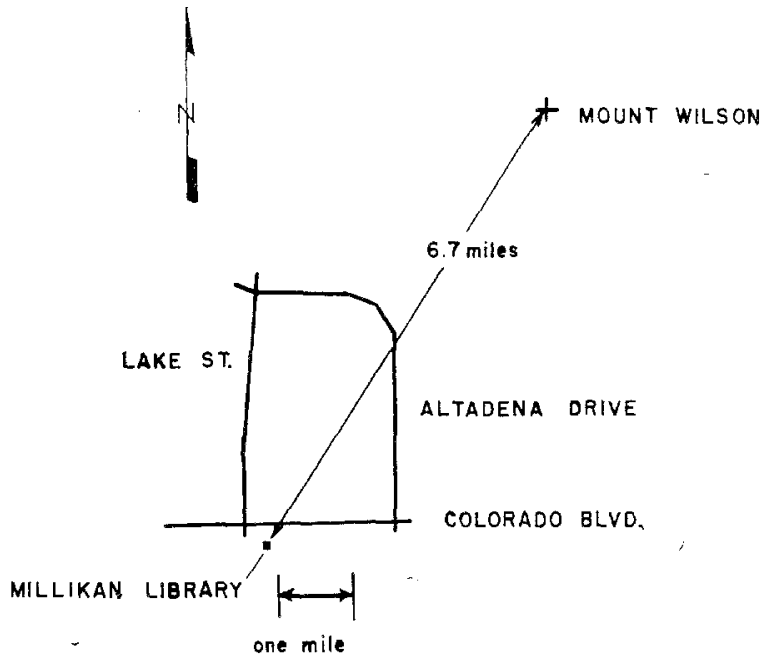

Frg. 3. Location of Mt. Wilson with respect to Millikan Library and the area shown in Figure 2.

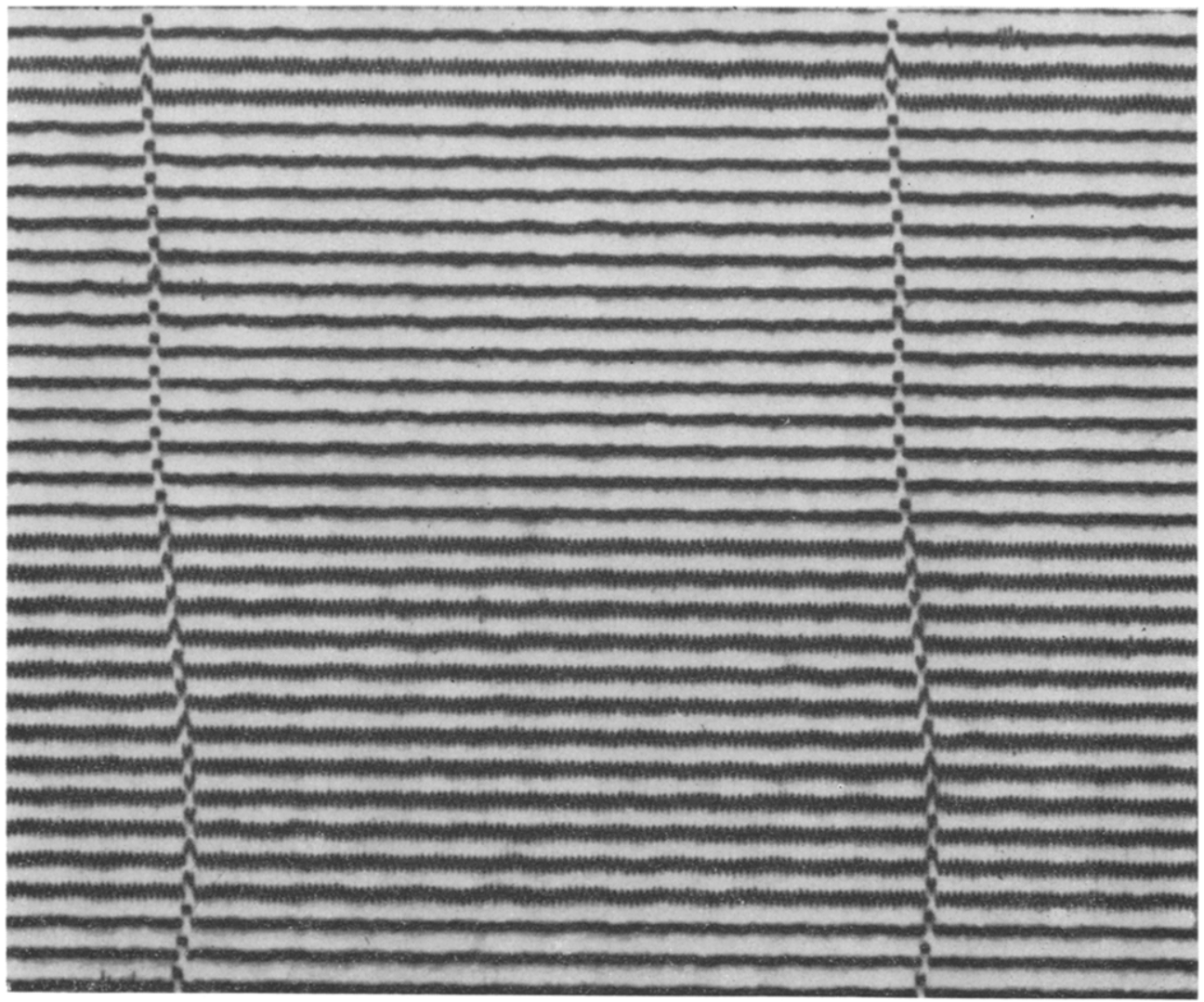

FIg. 4. A portion of the seismogram (vertical motion) from the Mt. Wilson Station for December 15/16 1966 . 
shown in Figure 2. The northernmost measurement is at the base of the hills which. rise to form the San Gabriel Mountains. The numbers in Figure 2 are such that 100; corresponds to the motion recorded by the seismometers at the calibration point.

Mount Wilson, elevation $5710 \mathrm{ft}$, lies 6.7 miles from the Millikan Library as shown in Figure 3, and its elevation is approximately $4,800 \mathrm{ft}$ higher than the Library site. A portion of the seismographic record of vertical motion for December 15/16 1966 is given in Figure 4. The time signals occur at minute intervals. The drum revolves four times per hour so that adjacent rows in Figure 4 are 15 min apart. The sinusoidal motion in the upper part of the figure was generated during the calibration test and the lower portion of Figure 4 is from the test proper. An enlarged view of the central

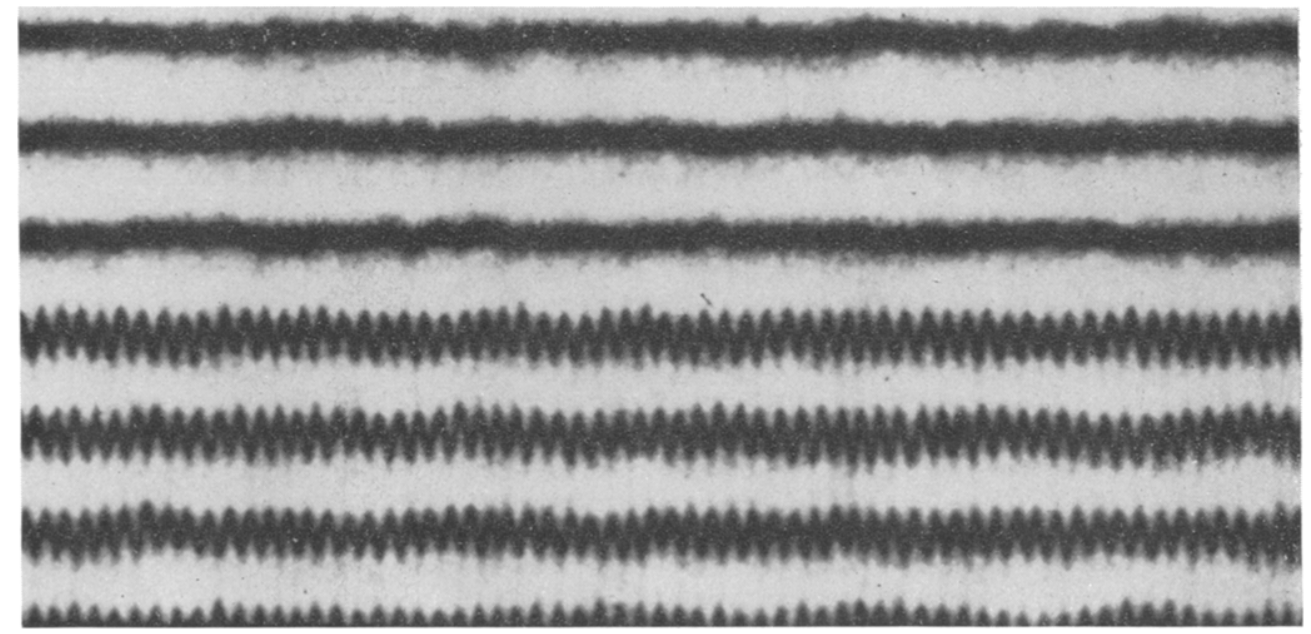

FIG. 5. An enlarged view from the center of Figure 4.

TABLE 1

Approximate Amplitudes of Response

\begin{tabular}{|c|c|}
\hline Location & $\begin{array}{l}\text { Relative } \\
\text { Amplitude }\end{array}$ \\
\hline Millikan Library, ninth floor $\left(2.04 \times 10^{-2} \mathrm{~g}\right)$ & 1600 \\
\hline Millikan Library, first floor & 150 \\
\hline Calibration point & 100 \\
\hline 3 blocks & 10 \\
\hline 3 miles & 1 \\
\hline Mt. Wilson, 6.7 miles (vertical) & 0.02 \\
\hline
\end{tabular}

portion of Figure 4 is shown in Figure 5. Although the signal-to-noise ratio is only about two, the nature of the motion makes it clearly discernible. The frequency of the motion is the same as that recorded at the Library site. From instrumental constants (James Brune, personal communication) the vertical acceleration at Mt. Wilson was found to be $3.2 \times 10^{-7} \mathrm{~g}$. Motion was not recorded at any of the more distant stations in the local network operated by the Seismological Laboratory.

The relative amplitudes of the motion are indicated in Table 1 in which the numbers are consistent with Figure 2. The recorded motions diminish at about the same rate, both to the north and to the west. Although the data are insufficient to establish a precise trend of amplitude with radius, $R$, the decay seems to lie in the range between $R^{-1}$ and $R^{-3 / 2}$. 


\section{Conclusions}

It is not difficult to show that a multistory building is particularly well-suited for exciting motions such as reported herein with relatively small equipment. The maximum force exerted by the two vibrators in the test was about $5.6 \times 10^{3} \mathrm{lb}$. From the mass of the building and its measured N-S fundamental mode shape (Jennings and Kuroiwa, 1968), and from the response in this test, the sinusoidal force and moment imposed by the building on the soil were found to be approximately $2.0 \times 10^{5} \mathrm{lb}$ and $2.8 \times 10^{8}$ in-lb, respectively. To apply such forces directly to the soil would require relatively large equipment.

Similarly, if a resonating system were designed to produce a translational force of the required magnitude, such as the system shown in Figure 6 , it is found again that the installation seems prohibitively large. For example, using the two vibration generators which can produce an oscillating force with a maximum of $10^{4} \mathrm{lb}$, and limiting the displacement of the mass in Figure 6 to 1 in (for stability of the vibration generators), it is found that for 2.5 per cent damping, the mass, $M$, must weigh $5 \times 10^{5}$ $\mathrm{lb}$ to produce a translational force of $2.0 \times 10^{5} \mathrm{lb}$. This mass is about one-fifth that of the Millikan Library Building.

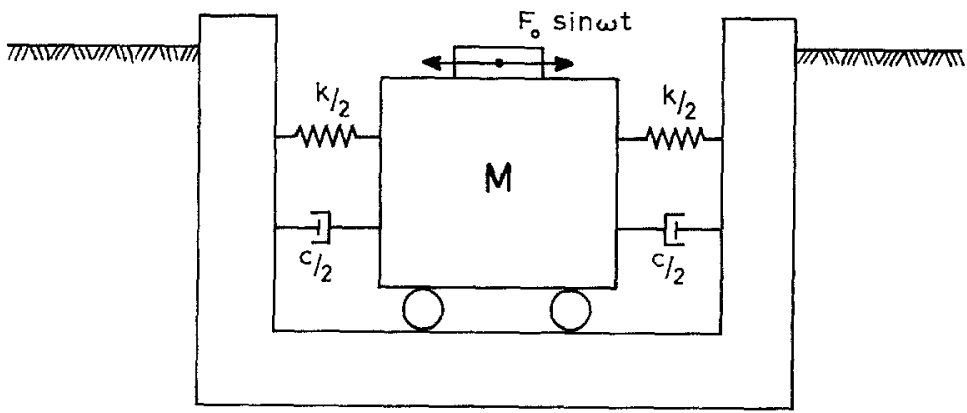

FIG. 6. Schematic drawing of a resonating system designed to produce large forces in the ground.

Forces of the magnitude of those above will be generated by the University of California, Berkeley, shaking table facility at the Richmond Field Station. Efforts are being made to measure the distant motions in the San Francisco Bay area that appear likely to be produced by the operation of this facility ( $P$. W. Rodgers, personal communication).

The principal advantage of the technique used in the experiment reported herein is that it allows relatively large forces to be generated with small equipment. The test procedure is limited, of course, by the necessity of having a building that can be vibrated, and, for a particular building, by being restricted to a small number of resonant frequencies.

From the results of this exploratory test, it would seem that this technique could be useful for testing the applicability of solutions of problems in the dynamics of elastic media to the phenomenon of soil-structure interaction. Also, it may be a useful way to measure the effects of local geology on dynamic motions and to ascertain average soil properties over distances of the order of miles.

\section{ACKNOWLEDGMENTS}

The writer is indebted to Clarence R. Allen, Ronald F. Scott and Francis E. Lehner for operating the seismographic instruments and to Julio Kuroiwa, Fred MeDonald, and Rafael Ronderos for assisting with the vibration equipment and the accelerometer-recorder system. 
The experiment was funded, in part, by the National Science Foundation under Grant GK$1197 \mathrm{X}$.

\section{REFERENCES}

Hudson, D. E. (1962). Synchronized Vibration Generators for Dynamic Tests of Full Scale Structures, Earthquake Engineering Research Laboratory, California Institute of Technology, Pasadena.

Jennings, P. C. and Kuroiwa, J. H. (1968). Vibration and soil-structure interaction tests of a nine-story reinforced concrete building, Bull. Seism. Soc. Am. 58, 891-916.

Kuroiwa, J. H. (1967). Vibration Test of a Multistory Building, Earthquake Engr. Research Lab., Calif. Inst. of Tech., Pasadena.

Lehner, F. E. and F. Press (1966). A mobile seismograph array, Bull. Seism. Soc. Am. 56, 889897.

Division of Engineering and Applied Science

California Institute of Technology

Pasadena, California 91109

Manuscript received June $9 \quad 1970$ 